\title{
Research Paper: Evaluation of Decision-making Units in Reducing Traffic Accidents Using Data Envelopment Analysis
}

\author{
${\text { Mohammad Reza Omidi }{ }^{*} \odot \text {, Nabi Omidi² }}^{2}$, Asad Mahmoudian Azar Sharabiani ${ }^{3}$
}

1. Department of Industrial Engineering, Faculty of Industrial Engineering, South Tehran Branch, Islamic Azad University, Tehran, Iran

2. Department of Management, Payame Noor University of Tehran, Tehran, Iran.

3. Department of Industrial Engineering, Payame Noor University of Tehran, Tehran, Iran.

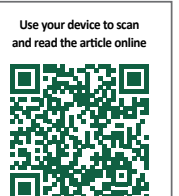

citation: Omidi MR, Omidi N, Mahmoudian Azar Sharabiani A. Evaluation of Decision-making Units in Reducing Traffic Accidents Using Data Envelopment Analysis. Health in Emergencies and Disasters Quarterly. 2019; 5(2):105-114. http://dx.doi. org/10.32598/hdq.5.2.222.7

http://dx.doi.org/10.32598/hdq.5.2.222.7

(c) (1) ()

Article info:

Received: 20 May 2019

Accepted: 03 Dec 2019

Available Online: 01 Jan 2020

\section{Keywords:}

Transportation, Accident, Efficiency

\section{ABSTRACT}

Background: Road accidents are one of the most important causes of death and severe bodily injuries and financial damages, and its social, cultural, and economic consequences have severely threatened human societies. The purpose of this study was to use Data Envelopment Analysis (DEA) to measure the efficiency of provincial traffic police in reducing accidents in 2018 and determining the amount of optimal input resources of each provincial unit.

Materials and Methods: The model used in this research had three inputs, including the level of equipment at the disposal, the level of the approved provincial budget, and the level of manpower at the disposal. It also had two outputs, including the score of reduction of casualties and the score of reduction of deaths in traffic accidents. The "returns to scale" was considered as a variable model, and the input model was an axial-type model. The DEAP software was used for data analysis.

Results: The highest decrease in deaths in traffic accidents (in 2018) was related to Fars Province with 119 people, and the highest decrease in the number of injured cases was related to Khorasan Razavi Province with 1495 people. The RAHVAR Police (Traffic Police of Iran) in Tehran Province had the highest level of input resources, including manpower, equipment, and approved budget. Performance measurement for 2018 showed that out of 31 provinces studied, 10 provinces had a good performance and 21 provinces had acted inefficiently. The research results showed that the proper allocation of resources could push all units to the brink of efficiency.

Conclusion: The trend of accidents in Iran is declining. Most of the RAHVAR Police units operate at an inefficient level, which by increasing their efficiency, the number of accidents can be reduced with a greater slope.

\section{* Corresponding Author:}




\section{Introduction}

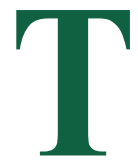

he increasing number of vehicles and road users is one of the important and wideranging issues with various and complex dimensions [1]. Traffic accidents are one of the new public health problems worldwide and are considered as one of the most important causes of death, physical disability, and hospitalization, which have significant economic and social consequences [2]. In the coming years, traffic accidents are expected to become the second leading cause of death in high-income and middle-income countries [3]. Research shows that by 2020 , the number of deaths due to traffic accidents will reach more than 2 million people worldwide, mostly in developing countries [4].

According to the World Health Organization, if the precautionary measures are not taken to reduce the current trend of accidents, the share of traffic accidents in mortality will increase to more than $67 \%$ [5]. Reducing the number of accidents as well as the severity of accidents should be considered and prioritized by the officials of the countries for their planning. Data show that 9 people die per 10,000 vehicles on the road in the world, while in Iran, 37 people die per 10,000 vehicles [6].

Human, technical, regulatory, and other factors are effective in the occurrence of accidents [7]. The most important factor in the occurrence of traffic accidents that has been addressed in various research is the human factor. One of the factors influencing the reduction of accidents is the improvement of drivers' supervision, which is the responsibility of the RAHVAR Police.

RAHVAR Police supervisory bodies can reduce the number of accidents by enacting appropriate rules, better monitoring, and training drivers [8]. One of the most important decisions in various organizations, including supervisory and service organizations is the efficient, appropriate, and fair allocation of financial resources to increase the efficiency of organizational units [9]. Targeted allocation of resources to the provincial units of the RAHVAR Police (as the administrator of monitoring and reducing accidents in Iran) can lead to better performance of this organization.

Furthermore, evaluating the efficiency of the provincial RAHVAR Police units allows them to be ranked in terms of efficiency in managing traffic accidents, and can be an indicator to identify the shortcomings of the provincial units and improve them. Given that the main responsibility for reducing accidents lies with the RAHVAR Police if they can act effectively, both the accidents will decrease and the general health of the community will increase, because they harm the individual and the community, as well.

Data envelopment analysis (DEA) has been widely used by researchers as a technique for ranking decisionmaking units [10-13]. In his study, which measured the efficiency of RAHVAR Police units, Zanguinejad described the efficiency of the decision-making units of each province but did not provide a model for the proper allocation of resources for RAHVAR Police [14].

DEA is effective in a system, and in addition to ranking and measuring performance, shows the correct allocation of resources between decision-making units. Jabbarzadeh and Sufi used DEA only to rank the police bases [15].

DEA has been used in RAHVAR Police for ranking and measuring the efficiency index, and no research has yet been done to determine the appropriate amount of resources available to the RAHVAR Police units

In this study, using DEA, in addition to measuring the efficiency of provincial RAHVAR Police in reducing accidents in 2018, the amount of optimal input resources of each provincial unit will be determined.

\section{Materials and Methods}

This descriptive and analytical study was of a comparative type, which used the data of injured and dead people in traffic accidents and the level of financial resources available for provincial units to measure the efficiency and estimate the appropriate resources needed by each province. The statistical population of this study was all the injured and dead cases in traffic accidents by provinces in 2018 received from the Iranian Legal Medicine Organization and the RAHVAR Police.

The purpose of this research was to measure the efficiency of RAHVAR Police; therefore, only the statistical data of accident deaths were mentioned because the supervision of RAHVAR Police as a response system was considered effective in reducing accidents and deaths in the country. The number of those who were injured or died due to vehicle defects or unsafe roads was not mentioned in this study.

Due to the confidentiality of the resources available to the RAHVAR Police, with the permission of the NAJA (Iranian Disciplinary Force) RAHVAR Police, the available indicators of each of the provincial RAHVAR Police were scored on a 0-100 index. The DEA tool was 
used to estimate the efficiency and optimal allocation of input resources for each province. The efficiency of the decision-making units in this research was determined by the input and output values.

The efficiency value was between $0-1$; number one indicated an efficient unit. The DEA model used in this study was the "variable returns to scale" model with 3 inputs and 2 outputs. The inputs of this model included the level of equipment available, the level of approved organizational budget, and the level of human resources available, whereas the outputs of this model included the reduction of traffic accident casualties and the reduction of traffic accident deaths.

The permit to review the level of resources available to the decision-making units was obtained from the RAHVAR Police, and considering its several aspects, with the cooperation of NAJA Research and Development staff, three input variables entitled "provincial approved budget level", "level of human resources available", and "level of equipment available" were used as input variables to measure the efficiency of decision-making units. For example, the amount of equipment available included a number of factors, such as the number of traffic enforcement cameras, the number of police vehicles, the quality of the police equipment, and surveillance and security devices. Based on the collection method of these resources, a level was considered for each province from 1-100, varied according to the amount of resources available in the studied provinces.

To measure the reduction in the number of traffic accident casualties, the base number was considered to be 2000 . When the number of injured cases decreased, the decreased number was added to 2000, and when the number of injured cases increased, the increased number was subtracted from 2000. The base number for those killed in traffic accidents was 500 .

After measuring the efficiency for 2018, the appropriate input to reach the efficiency limit was estimated and the correct form of resource allocation between units was determined. Considering that in this study the inputs of NAJA provincial units were centrally determined by the General Staff of NAJA and at a certain level, and on
Input sources for measuring the efficiency of the provincial units of RAHVAR Police

1. Manpower level available

2. Equipment level available

3. Provincial approved budget level

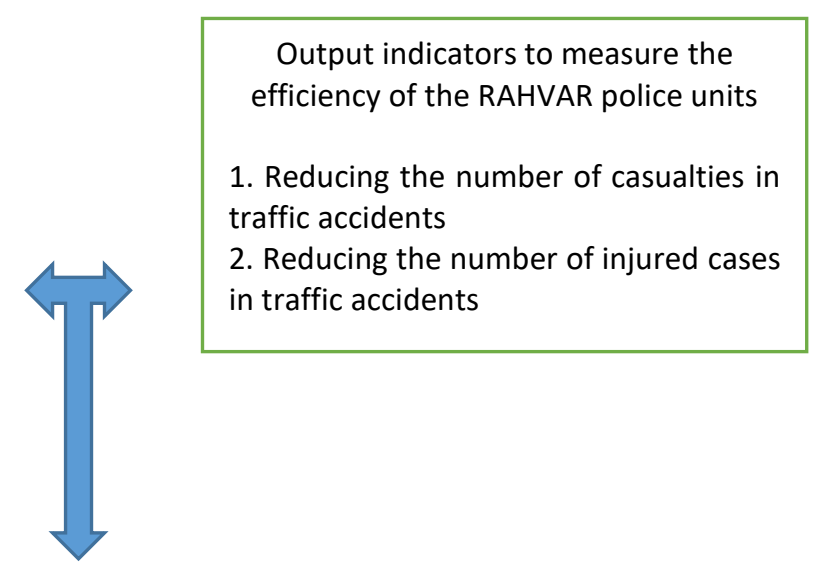

Measuring the efficiency of the RAHVAR Police units using 3 inputs and 2 outputs

Figure 1. Stages of the research flowchart 
the other hand, considering that the objective of NAJA is to develop and provide better services to people, the emphasis of the management of this assemblage was more on the amount of services based on the input sources of the provincial units of NAJA.

The model used in this study was input-oriented. Also, the DEA model with the assumption of variable returns to scale or the model of Banker, Charnes, and Cooper (BCC) was used.

To measure the validity of the instrument and check whether the input and output sources could be a suitable tool for measuring the efficiency of decision-making units, the opinions of professors and experts, including 10 faculty members with relevant fields were used. The experts confirmed the validity of the input and output sources. Because the study used real-world data and hospital performance data, it was not relevant to investigate the reliability of the study. Figure 1 shows a step-by-step flowchart of the research and performance measurement using DEA.

\section{Results}

The statistical data of injured and dead cases in traffic accidents in 2018 showed that compared with 2017, the number of people injured in traffic accidents decreased by $5.2 \%$ and the number of deaths in traffic accidents decreased by $2.7 \%$. The highest number of reduction in deaths in traffic accidents in 2018 was related to Fars Province with 119 cases, whereas the highest number of reduction in casualties was related to Khorasan Razavi Province with 1495 cases. The total number of casualties in 2017 and 2018, the rate of decrease and increase in statistical data, and the scores of the provincial RAHVAR Police are provided in Table 1.

Based on the available manpower, equipment, and approved budget, a level from 1 to 100 was determined for each province because of the involvement of many factors at each level available to the provincial police. The level available to each province is presented in Table 2 . RAHVAR Police of Tehran Province had the highest level of input resources, including manpower, equipment, and approved budget.

After measuring the inputs of the provincial units of RAHVAR Police in each province based on the levels of the approved budget, manpower, and equipment in 2018, using input and output resources, including the index of a decrease and an increase in traffic accident victims and the index of an increase and a decrease in traffic accident casualties, the efficiency of each province was measured (Table 3 ).
Performance measurement in 2018 showed that out of 31 provinces studied, 10 provinces had a good performance. Also, 21 out of 31 provinces studied, had acted inefficiently in 2018, which indicates the need to review the allocation of resources in the RAHVAR Police units. The mean efficiency of all decision-making units in this study for 2018 was 0.637 .

In DEA, decision-making units were divided into two categories of efficient and inefficient, and units with an efficiency of higher than 0.5 were identified as units with moderate efficiency, and those with an efficiency below 0.5 were identified as units with severe inefficiency [13]. Among the inefficient units, 8 units had a performance above $0.5 \%$, which indicates their average efficiency index, but 13 provinces had an efficiency of 0.5 , which indicates a serious waste of resources in these provinces. Also, among the efficient units, the number of references to achieve efficiency is given in Table 4 .

Appropriate allocation of the input resources for inefficient provinces to reach the efficiency limit was based on the reference provinces and lambda coefficients. The amount of input resources of the provinces and the desired amount of resources to reach the efficiency limit are provided in Table 5. The available input resources are shown on the left side of the arrows and the desired input resources are shown on the right side of the arrows.

\section{Discussion}

Every year, a large number of people lose their lives in Iran due to traffic accidents and natural disasters, and a significant number of these people are injured in accidents. The aim of this study was to use DEA to measure the efficiency of the RAHVAR Police units involved in reducing accidents and estimate available resources to reach the efficiency limit.

The results of this study showed that the number of people injured and dead in traffic accidents in Iran is declining. Reducing the number of accidents is a good indicator of the correct direction of accident management in the country, which can improve the unfavorable situation of the number of people killed and injured in traffic accidents.

In the research by Erfanpour et al. (2016), the incidence of accidents in Khorasan Province as one of the tourist destinations in Iran was declining [16]. Also. in a study by Ghorbani et al. (2012), accidents in Khuzestan Province had a decreasing trend [17]. Hosseinzadeh et al. investigated the trend of changes in traffic accidents in 
Table 1. Total number of casualties and scores of RAHVAR Police

\begin{tabular}{|c|c|c|c|c|c|c|c|c|}
\hline 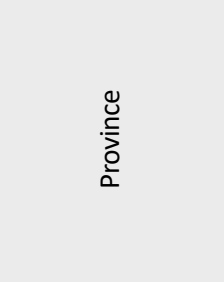 & 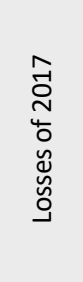 & 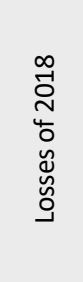 & 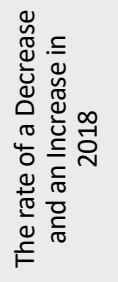 & 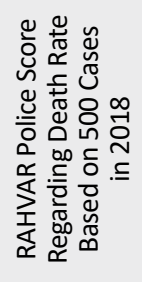 & 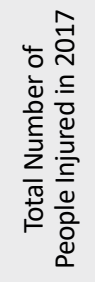 & 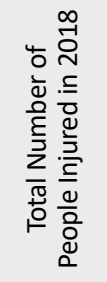 & 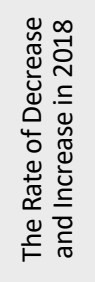 & 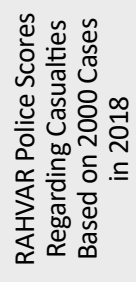 \\
\hline East Azarbaijan & 885 & 886 & 1 & 499 & 15492 & 15437 & -55 & 2055 \\
\hline West Azarbaijan & 622 & 548 & -74 & 574 & 9410 & 9352 & -58 & 2058 \\
\hline Isfahan & 477 & 405 & -72 & 572 & 9626 & 8922 & -704 & 2704 \\
\hline Ardabil & 160 & 172 & 12 & 488 & 4201 & 4324 & 123 & 1877 \\
\hline Alborz & 249 & 232 & -17 & 517 & 8800 & 8654 & -146 & 2146 \\
\hline Ilam & 199 & 238 & 39 & 461 & 2965 & 2549 & -416 & 2416 \\
\hline Bushehr & 289 & 287 & -2 & 502 & 3429 & 3623 & 194 & 1806 \\
\hline Tehran & 1352 & 1295 & -57 & 557 & 37943 & 35631 & -312 & 2312 \\
\hline $\begin{array}{c}\text { Chaharmahal and } \\
\text { Bakhtiari }\end{array}$ & 262 & 232 & -30 & 530 & 5300 & 5672 & 372 & 1628 \\
\hline South Khorasan & 240 & 247 & 7 & 493 & 3536 & 4262 & 726 & 1274 \\
\hline Khorasan Razavi & 1272 & 1265 & -7 & 507 & 25798 & 24303 & -1495 & 3495 \\
\hline North Khorasan & 299 & 234 & -65 & 565 & 4382 & 4469 & 87 & 1913 \\
\hline Khuzestan & 811 & 1172 & 361 & 139 & 17639 & 17503 & -136 & 2136 \\
\hline Kermanshah & 475 & 452 & -23 & 523 & 10172 & 11071 & 899 & 1101 \\
\hline Kohgiluyeh & 183 & 197 & 14 & 486 & 5032 & 4921 & -111 & 2111 \\
\hline Gilan & 341 & 312 & -29 & 529 & 9648 & 9973 & 325 & 1675 \\
\hline Golestan & 286 & 274 & -12 & 512 & 9026 & 8429 & -597 & 2597 \\
\hline Mazandaran & 414 & 432 & 18 & 482 & 1624 & 17437 & 1196 & 804 \\
\hline Lorestan & 442 & 460 & 18 & 482 & 8680 & 7513 & -1167 & 3167 \\
\hline Qazvin & 186 & 175 & -11 & 511 & 4972 & 4545 & -427 & 2000 \\
\hline Qom & 223 & 151 & -72 & 572 & 9273 & 9420 & 147 & 1853 \\
\hline Kurdistan & 221 & 206 & -15 & 515 & 4717 & 4469 & -248 & 2248 \\
\hline Fars & 1445 & 1326 & -119 & 619 & 24252 & 23778 & -474 & 2474 \\
\hline Kerman & 212 & 200 & -12 & 512 & 6304 & 5284 & -1020 & 3020 \\
\hline Markazi & 488 & 376 & -112 & 612 & 5884 & 5968 & 84 & 1916 \\
\hline Hamedan & 389 & 336 & -53 & 553 & 6646 & 5737 & -909 & 2909 \\
\hline Hormozgan & 331 & 369 & 38 & 462 & 2871 & 3414 & 543 & 1457 \\
\hline Yazd & 223 & 269 & 46 & 454 & 2521 & 2624 & 103 & 1897 \\
\hline Zanjan & 216 & 222 & 6 & 494 & 3254 & 3142 & -112 & 2112 \\
\hline Semnan & 201 & 219 & 18 & 482 & 2514 & 2715 & 201 & 1799 \\
\hline $\begin{array}{l}\text { Sistan and } \\
\text { Baluchestan }\end{array}$ & 196 & 182 & -14 & 514 & 2647 & 2345 & -302 & 2302 \\
\hline
\end{tabular}


Table 2. The level of input resources of RAHVAR Police in the provinces

\begin{tabular}{|c|c|c|c|c|c|}
\hline Province & $\begin{array}{l}\text { Provincial Ap- } \\
\text { proved Budget } \\
\text { Level }\end{array}$ & $\begin{array}{c}\text { Manpower Level } \\
\text { Available }\end{array}$ & $\begin{array}{c}\text { Equipment Level } \\
\text { Available }\end{array}$ & Death Output & Injured Output \\
\hline East Azarbaijan & 33.16 & 33.17 & 32.07 & 499 & 2055 \\
\hline West Azarbaijan & 41.14 & 32.20 & 28.21 & 574 & 2058 \\
\hline Isfahan & 52.17 & 40.12 & 50.10 & 572 & 2704 \\
\hline Ardabil & 17.14 & 15.21 & 15.12 & 488 & 1877 \\
\hline Alborz & 24.12 & 20.15 & 52.31 & 517 & 2146 \\
\hline Ilam & 11.09 & 17.12 & 18.19 & 461 & 2416 \\
\hline Bushehr & 17.14 & 15.16 & 17.19 & 502 & 1806 \\
\hline Tehran & 100 & 100 & 100 & 557 & 2312 \\
\hline Chaharmahal & 32.14 & 21.23 & 32.14 & 530 & 1628 \\
\hline South Khorasan & 13.19 & 14.12 & 10.07 & 493 & 1274 \\
\hline Khorasan Razavi & 70.51 & 61.17 & 72.25 & 507 & 3495 \\
\hline North Khorasan & 12.14 & 9.25 & 10.27 & 565 & 1913 \\
\hline Khuzestan & 64.14 & 64.32 & 59.81 & 139 & 2136 \\
\hline Kermanshah & 60.21 & 59.41 & 52.12 & 523 & 1101 \\
\hline Kohgiluyeh & 7.86 & 10.13 & 11.09 & 486 & 2111 \\
\hline Gilan & 50.51 & 22.13 & 22.36 & 529 & 1675 \\
\hline Golestan & 42.14 & 23.45 & 44.14 & 512 & 2597 \\
\hline Mazandaran & 62.61 & 42.14 & 64.15 & 482 & 804 \\
\hline Lorestan & 26.24 & 14.25 & 24.97 & 482 & 3167 \\
\hline Qazvin & 34.12 & 26.16 & 28.76 & 511 & 2000 \\
\hline Qom & 23.17 & 21.12 & 29.12 & 572 & 1853 \\
\hline Kurdistan & 13.14 & 15.02 & 14.72 & 515 & 2248 \\
\hline Fars & 60.12 & 34.14 & 42.12 & 619 & 2474 \\
\hline Kerman & 11.13 & 10.09 & 13.14 & 512 & 3020 \\
\hline Markazi & 16.10 & 22.41 & 41.16 & 612 & 1916 \\
\hline Hamedan & 22.34 & 23.19 & 30.30 & 553 & 2909 \\
\hline Hormozgan & 34.82 & 24.51 & 32.12 & 462 & 1457 \\
\hline Yazd & 28.80 & 20.12 & 32.71 & 454 & 1897 \\
\hline Zanjan & 27.40 & 26.14 & 20.13 & 494 & 2112 \\
\hline Semnan & 22.20 & 20.14 & 40.12 & 482 & 1799 \\
\hline Sistan and Baluchestan & 9.84 & 15.05 & 28.17 & 514 & 2302 \\
\hline
\end{tabular}

Table 3. Performance of the RAHVAR Police units in 2018

\begin{tabular}{ccc}
\hline Province & Performance Level & Efficiency \\
\hline East Azarbaijan & Inefficient & 0.334 \\
\hline West Azarbaijan & Inefficient & 0.59 \\
\hline Isfahan & Inefficient & 0.627 \\
\hline Ardabil & Inefficient & 0.684 \\
\hline Alborz & Inefficient & 0.473 \\
Ilam & Inefficient & 0.808 \\
\hline
\end{tabular}




\begin{tabular}{|c|c|c|}
\hline Province & Performance Level & Efficiency \\
\hline Bushehr & Inefficient & 0.629 \\
\hline Tehran & Inefficient & 0.163 \\
\hline Chaharmahal & Inefficient & 0.436 \\
\hline South Khorasan & Good performance & 1 \\
\hline Khorasan Razavi & Good performance & 1 \\
\hline North Khorasan & Good performance & 1 \\
\hline Khuzestan & Inefficient & 0.182 \\
\hline Kermanshah & Inefficient & 0.198 \\
\hline Kohgiluyeh & Good performance & 1 \\
\hline Gilan & Inefficient & 0.458 \\
\hline Golestan & Inefficient & 0.417 \\
\hline Mazandaran & Inefficient & 0.22 \\
\hline Lorestan & Good performance & 1 \\
\hline Qazvin & Inefficient & 0.365 \\
\hline Qom & Inefficient & 0.549 \\
\hline Kurdistan & Inefficient & 0.766 \\
\hline Fars & Good performance & 1 \\
\hline Kerman & Good performance & 1 \\
\hline Markazi & Good performance & 1 \\
\hline Hamedan & Good performance & 1 \\
\hline Hormozgan & Inefficient & 0.377 \\
\hline Yazd & Inefficient & 0.46 \\
\hline Zanjan & Inefficient & 0.536 \\
\hline Semnan & Inefficient & 0.475 \\
\hline Sistan and Baluchestan & Good performance & 1 \\
\hline
\end{tabular}

Table 4. The number of efficient units

\begin{tabular}{cc}
\hline Province & Number \\
\hline South Khorasan & 2 \\
\hline Khorasan Razavi & 1 \\
\hline North Khorasan & 21 \\
\hline Kohgiluyeh & 10 \\
\hline Lorestan & 1 \\
\hline Fars & 4 \\
\hline Kerman & 12 \\
\hline Markazi & 2 \\
\hline Hamedan & 3 \\
\hline Sistan and Baluchestan & 1 \\
\hline
\end{tabular}


Table 5. Input and input target values

\begin{tabular}{|c|c|c|c|}
\hline Province & Input 1 & Input 2 & Input 3 \\
\hline East Azarbaijan & $33.16 \rightarrow 11.072$ & $33.17 \rightarrow 9.525$ & $32.07 \rightarrow 10.708$ \\
\hline West Azarbaijan & $41.14 \rightarrow 21.568$ & $32.2 \rightarrow 14.183$ & $28.21 \rightarrow 16.639$ \\
\hline Isfahan & $52.17 \rightarrow 32.693$ & $40.12 \rightarrow 24.733$ & $50.1 \rightarrow 31.396$ \\
\hline Ardabil & $17.14 \rightarrow 11.731$ & $15.21 \rightarrow 9.334$ & $15.12 \rightarrow 10.348$ \\
\hline Alborz & $24.12 \rightarrow 11.397$ & $20.15 \rightarrow 9.521$ & $52.31 \rightarrow 10.914$ \\
\hline Ilam & $11.09 \rightarrow 8.957$ & $17.12 \rightarrow 10.117$ & $18.19 \rightarrow 11.778$ \\
\hline Bushehr & $17.14 \rightarrow 10.775$ & $15.16 \rightarrow 9.531$ & $17.19 \rightarrow 10.531$ \\
\hline Tehran & $100 \rightarrow 16.31$ & $100 \rightarrow 13.405$ & $100 \rightarrow 16.31$ \\
\hline Chaharmahal & $32.14 \rightarrow 12.14$ & $21.23 \rightarrow 9.25$ & $32.14 \rightarrow 10.27$ \\
\hline South Khorasan & $13.19 \rightarrow 13.19$ & $14.12 \rightarrow 14.12$ & $10.07 \rightarrow 10.07$ \\
\hline Khorasan Razavi & $70.51 \rightarrow 70.51$ & $61.17 \rightarrow 61.17$ & $72.25 \rightarrow 72.25$ \\
\hline North Khorasan & $12.14 \rightarrow 12.14$ & $9.25 \rightarrow 9.25$ & $10.27 \rightarrow 10.27$ \\
\hline Khuzestan & $64.14 \rightarrow 11.656$ & $64.32 \rightarrow 9.469$ & $59.81 \rightarrow 10.869$ \\
\hline Kermanshah & $60.21 \rightarrow 11.914$ & $59.41 \rightarrow 9.296$ & $52.12 \rightarrow 10.313$ \\
\hline Kohgiluyeh & $7.86 \rightarrow 7.86$ & $10.13 \rightarrow 10.13$ & $11.09 \rightarrow 11.09$ \\
\hline Gilan & $50.51 \rightarrow 12.329$ & $22.13 \rightarrow 10.129$ & $22.36 \rightarrow 10.234$ \\
\hline Golestan & $42.14 \rightarrow 11.516$ & $23.45 \rightarrow 9.769$ & $44.14 \rightarrow 12.043$ \\
\hline Mazandaran & $62.61 \rightarrow 12.14$ & $42.14 \rightarrow 9.25$ & $64.15 \rightarrow 10.27$ \\
\hline Lorestan & $26.24 \rightarrow 26.24$ & $14.25 \rightarrow 14.25$ & $24.97 \rightarrow 24.97$ \\
\hline Qazvin & $34.12 \rightarrow 12.061$ & $26.16 \rightarrow 9.316$ & $28.76 \rightarrow 10.496$ \\
\hline Qom & $23.17 \rightarrow 12.73$ & $21.12 \rightarrow 11.21$ & $29.12 \rightarrow 14.871$ \\
\hline Kurdistan & $13.14 \rightarrow 10.061$ & $15.02 \rightarrow 9.82$ & $14.72 \rightarrow 11.271$ \\
\hline Fars & $60.12 \rightarrow 60.12$ & $34.14 \rightarrow 34.14$ & $42.12 \rightarrow 42.12$ \\
\hline Kerman & $11.13 \rightarrow 11.13$ & $10.09 \rightarrow 10.09$ & $13.14 \rightarrow 13.14$ \\
\hline Markazi & $16.1 \rightarrow 16.1$ & $22.41 \rightarrow 22.41$ & $41.16 \rightarrow 41.16$ \\
\hline Hamedan & $22.34 \rightarrow 22.34$ & $23.19 \rightarrow 23.19$ & $30.3 \rightarrow 30.3$ \\
\hline Hormozgan & $34.82 \rightarrow 12.14$ & $24.51 \rightarrow 9.25$ & $32.12 \rightarrow 10.27$ \\
\hline Yazd & $28.8 \rightarrow 12.14$ & $20.12 \rightarrow 9.25$ & $32.71 \rightarrow 10.27$ \\
\hline Zanjan & $27.4 \rightarrow 11.958$ & $26.14 \rightarrow 9.401$ & $20.13 \rightarrow 10.786$ \\
\hline Semnan & $22.2 \rightarrow 10.555$ & $20.14 \rightarrow 9.576$ & $40.12 \rightarrow 10.574$ \\
\hline Sistan and Baluchestan & $9.84 \rightarrow 9.84$ & $15.05 \rightarrow 15.05$ & $28.17 \rightarrow 28.17$ \\
\hline
\end{tabular}

Qazvin Province and reported that the rate of accidents in this province has been almost unchanged [18].

Assessing the efficiency of RAHVAR Police units in 2018 showed that $30 \%$ of its units were at an efficient level and $70 \%$ were inefficient. This shows the need to reconsider the proper allocation of resources among RAHVAR Police units for better control and supervision of the drivers. The results of this study showed that DEA was an effective tool for measuring the efficiency of decision-making units.
Alinejad and Khalili (2017) in their research showed that DEA was a suitable tool to measure the efficiency of hospitals [19]. Fazeli et al. used DEA as a tool to measure the efficiency of hospitals in Ilam and indicated that this method was acceptable in measuring efficiency when there are many decision-making units [20].

Given that the reference units are currently identified, it is suggested that an analysis of the experiences and reference actions be performed, and resources be allocated to the follower provinces to reduce the accident rate. Different bodies are involved in road safety and accidents. In this study, only the RAHVAR Police was investigated. Involv- 
ing other effective bodies to make a more accurate assessment of the allocation of provincial resources is suggested.

The limitations of this study were as follows:

- It was very difficult to receive information from the introduced experts due to their busy schedule and in some cases, their conservatism;

- The administrative process for obtaining a permit to receive statistical data from the police was a long procedure;

- Due to the involvement of many cases in measuring performance and selecting input indicators, the available level was used instead of the actual values.

\section{Ethical Considerations}

\section{Compliance with ethical guidelines}

All ethical principles are considered in this article.

Funding

This research did not receive any grant from funding agencies in the public, commercial, or non-profit sectors.

\section{Authors' contributions}

All authors contributed in preparing this article.

\section{Conflict of interest}

The authors declared no conflict of interest.

\section{References}

[1] Kurakina E, Evtiukov S, Rajczyk J. Forecasting of road accident in the DVRE system. Transportation Research Procedia. 2018; 36:380-5. [DOI:10.1016/j.trpro.2018.12.111]

[2] Fountas G, Anastasopoulos PC, Mannering FL. Analysis of vehicle accident-injury severities: A comparison of segmentversus accident-based latent class ordered probit models with class-probability functions. Analytic Methods in Accident Research. 2018; 18:15-32. [DOI:10.1016/j.amar.2018.03.003]

[3] Grant E, Salmon PM, Stevens NJ, Goode N, Read GJ. Back to the future: What do accident causation models tell us about accident prediction? Safety Science. 2018; 104:99-109. [DOI:10.1016/j.ssci.2017.12.018]

[4] Zhang X, Pang Y, Cui M, Stallones L, Xiang H. Forecasting mortality of road traffic injuries in China using seasonal autoregressive integrated moving average model. Annals of Epidemiology. 2015; 25(2):101-6. [DOI:10.1016/j.annepidem.2014.10.015] [PMID]

[5] Fountas G, Anastasopoulos PC. Analysis of accident injury-severity outcomes: The zero-inflated hierarchical ordered probit model with correlated disturbances. Analytic Methods in Accident Research. 2018; 20:30-45. [DOI:10.1016/j.amar.2018.09.002]

[6] Ahmadabadi AA, Heravi G. The effect of critical success factors on project success in Public-Private Partnership projects: A case study of highway projects in Iran. Transport Policy. 2019; 73:152-61. [DOI:10.1016/j.tranpol.2018.07.004]

[7] Bakhtiyari M, Delpisheh A, Riahi SM, Latifi A, Zayeri F, Salehi M, et al. Epidemiology of occupational accidents among Iranian insured workers. Safety Science. 2012; 50(7):1480-4. [DOI:10.1016/j.ssci.2012.01.015]

[8] Omidi N, Omidi MR. Estimating accident-related traumatic injury rate by future studies models in Semnan Province, Iran Health in Emergencies \& Disasters Quarterly (HDQ). 2018; 3(4):191-8. [DOI:10.32598/hdq.3.4.191]

[9] Yan L, Tong W, Hui D, Zongzhi W. Research and application on risk assessment DEA model of crowd crushing and trampling accidents in subway stations. Procedia Engineering. 2012; 43:494-8. [DOI:10.1016/j.proeng.2012.08.085]

[10] Regalado López FJ, Campos Cacheda JM. An approximation to technical efficiency in Spanish toll roads through a DEA approach. Transportation Research Procedia. 2018; 33:386-93. [DOI:10.1016/j.trpro.2018.11.005]

[11] Halkos G, Petrou KN. Assessing 28 EU member states' environmental efficiency in national waste generation with DEA. Journal of Cleaner Production. 2019; 208:509-21. [DOI:10.1016/j.jclepro.2018.10.145]

[12] Sueyoshi T, Yuan Y, Li A, Wang D. Methodological comparison among radial, non-radial and intermediate approaches for DEA environmental assessment. Energy Economics. 2017; 67:439-53. [DOI:10.1016/j.eneco.2017.07.018]

[13] Izadikhah M, Saen RF. Assessing sustainability of supply chains by chance-constrained two-stage DEA model in the presence of undesirable factors. Computers \& Operations Research. 2018; 100:343-67. [DOI:10.1016/j.cor.2017.10.002]

[14] Zangoueinezhad A. [Indices for efficiency measurement in NAJA provincial units: A Data Envelopment Analysis approach (Persian)]. Supervision \& Inspection. 2009; 9(1388):7-38.

[15] Jabarzadeh Y, Soufi A. [Efficiency evaluation and ranking of provincial inspection departments of NAJA using coating data analysis (Persian)]. Supervision \& Inspection. 2012; 18(1390):85-103.

[16] Erfanpoor S, Hashemi Nazari SS, Ghadirzadeh M. [An epidemiology study of fatal road traffic accidents in Khorasan Razavi Province in 2011 (Persian)]. Medical Journal Of Mashhad University Of Medical Sciences. 2016; 59(4):261-8.

[17] Ghorbani Birgani A, Hakim A, Zare K. Epidemiologic study of fatal traffic accidents in the Khuzestan Province, Iran in 1389. J of Rescue and Relief. 2012; 4(2):0-0. http:/ /jorar.ir/ article-1-118-en.html

[18] Hosseinzadeh K, Sadegh R, Sadghi Oskuyi SS, Shahsavari M. Survey the status and trend of traffic accidents in Qazvin Province (2006-2015). Journal of Qazvin University of Medi- 
cal Sciences (JQUMS). 2017; 21(1):38-44. http://journal.qums. ac.ir/article-1-2162-en.html

[19] Alinezhad A, Khalili J. Performance Evaluation Model for hospitals using BSC and fuzzy VFB-DEA. Journal of Development Economics and Planning. 2017; 7(2):2. http://jdep. iaukhsh.ac.ir/article_536821_en.html

[20] Fazeli E, Vafaei F, Jamshidi NB. [Investigation on efficacy of the hospitals affiliated to Ilam University of Medical Sciences by DEA method (Persian)]. Scientific Journal of Ilam University of Medical Sciences. 2015; 23(1):89-97. http:// sjimu.medilam.ac.ir/article-1-2095-en.html 